\title{
Editorial
}

\section{Care of the Neurological Patient in the Medical ICU}

\author{
Rubin I. Cohen*\$
}

\begin{abstract}
The Division of Pulmonary, Sleep and Critical Care Medicine, 410 Lakeville Rd, Suite 107, New Hyde Park, NY, The Hofstra-North Shore LIJ School of Medicine, USA
\end{abstract}

Following a period of dormancy during the 1960s and 1970 s, neurological intensive care slowly evolved into its own specialty with the recognition of the unique physiology and sensitivity to injury that affects the central nervous system (CNS) and the realization of the role the CNS plays in critical illness $[1,2]$. In spite of this, many hospitals do not provide dedicated neurological intensive care and patients are cared for in non-specialized critical care units. Moreover, the outlook for many neurological disorders had previously been one of nihilism. However, fundamental understanding of pathophysiology and translation of research from bench to bedside combined with data from large randomized clinical trials are beginning to turn this nihilistic tide. Therefore, there is a great need to communicate scientific findings in neurological intensive care to the larger critical care community who may not be familiar with this rapidly evolving field.

The purpose of this issue is to provide guidance to medical intensivists in the care of several neurological conditions. We review causes and treatments of increased intracerebral pressure and its brain-focused management. The management of blood pressure in critical care neurology especially following cerebro-vascular accidents remains controversial, however recent randomized trial have clarified some of the issues and these are discussed in another article in this review [3].

Few aspects of critical care have undergone the rapid evolution that the use of sedatives had witnessed. The critical

*Address correspondence to this author at the North Shore-LIJ Division of Pulmonary, Sleep and Critical Care Medicine, The Hofstra North Shore-LIJ School of Medicine, 410 Lakeville Rd, Suite 107, New Hyde Park, NY 11040, USA; Tel: 01 516-465-5400; Fax: 01516465 5454;

E-mail: rocohen@nshs.edu

${ }^{\S}$ Guest Editor care community has shifted from a culture of nearly universal deep sedation for days on end, to one that embraces a more awake and interactive state. The role of the intensivists has also evolved to one that minimizes iatrogenic injury. Indeed, we in the critical care community now recognize that critically ill patients are vulnerable to acute and long-lasting CNS injury that could be impacted upon by the indiscriminate use of sedatives. Excessive sedation also leads to prolonged ventilator time and increases morbidity. Acute injury such as delirium is now considered a feature of multiple organ dysfunction syndrome and could evolve into long term cognitive impairment. For these reasons, we review the use of sedatives and pain medications, as well as acute delirium the ICU and outline the most recent recommendations $[4,5]$.

The ICU presents one of the harshest environments for initiating and maintaining sleep. The consequence of disturbing the natural circadian rhythm in the ICU in not usually appreciated. We include an article on sleep in the ICU outlining the mechanisms of sleep disruption, and how sleep deprivation affects human biology [6]. Lastly, we discuss limbic encephalopathy. While this is rare disorder, it is one that combines the realms of psychiatric illnesses, seizures, oncology and critical care, and is a disorder that is amenable to therapy.

\section{REFERENCES}

[1] Bleck TP. Historical aspects of critical care and the nervous system. Crit Care Clin 2009; 25(1): 153-64.

[2] Bleck TP. Neurological complications in critical illness: a focus on mechanisms. Foreword. Crit Care Clin 2008; 24(1): xiii-xiv.

[3] Frontera JA. Blood pressure in intracerebral hemorrhage--how low should we go? N Engl J Med 2013; 368(25): 2426-7.

[4] Peitz GJ, Balas MC, Olsen KM, Pun BT, Ely EW. Top 10 myths regarding sedation and delirium in the ICU. Crit Care Med 2013; 41(9 Suppl 1): S46-56.

[5] Pandharipande P, Ely W. Sedation and analgesia in the ICU: pharmacology protocolization, and clinical consequences. Crit Care Clin 2009; 25: xv-xvi.

[6] Salas RE, Gamaldo CE. Adverse effects of sleep deprivation in the ICU. Crit Care Clin 2008; 24: 461-76.

(C) Rubin I. Cohen; Licensee Bentham Open.

This is an open access article licensed under the terms of the Creative Commons Attribution Non-Commercial License (http://creativecommons.org/licenses/by-nc/ 3.0/) which permits unrestricted, non-commercial use, distribution and reproduction in any medium, provided the work is properly cited. 